\title{
Oral Cavity Cyst
}

National Cancer Institute

\section{Source}

National Cancer Institute. Oral Cavity Cyst. NCI Thesaurus. Code C4759.

A cystic lesion located in the oral cavity. 